\title{
Bioinformatics characterization of Plasmodium knowlesi apical membrane antigen 1 (PkAMA1) for multi-epitope vaccine design
}

\author{
Azazi, A. ${ }^{1}$, Haron, F.N. ${ }^{1}$, Chua, K.H. ${ }^{2}$, Lim, Y.A.L. ${ }^{3,4}$, Lee, P.C. ${ }^{5}$, Chew, C.H. ${ }^{1 *}$ \\ ${ }^{1}$ Faculty of Health Sciences, Universiti Sultan Zainal Abidin, 21300 Kuala Nerus, Terengganu, Malaysia \\ 2Department of Biomedical Science, Faculty of Medicine, Universiti Malaya, 50603 Kuala Lumpur, Malaysia \\ ${ }^{3}$ Department of Parasitology, Faculty of Medicine, Universiti Malaya, 50603 Kuala Lumpur, Malaysia \\ ${ }^{4}$ Centre of Excellence for Research in AIDS (CERiA), Universiti Malaya, 50603 Kuala Lumpur, Malaysia \\ ${ }^{5}$ Faculty of Science and Natural Resources, Universiti Malaysia Sabah, Jalan UMS, 88400 Kota Kinabalu, Sabah, Malaysia \\ *Corresponding author: chinghoong80@yahoo.com; chewch@unisza.edu.my
}

\section{ARTICLE HISTORY}

Received: 23 March 2021

Revised: 11 June 2021

Accepted: 11 June 2021

Published: 31 July 2021

\begin{abstract}
Malaria caused by Plasmodium knowlesi species has become a public health concern, especially in Malaysia. Plasmodium knowlesi parasite which originates from the macaque species, infects human through the bite of the Anopheles mosquitoes. Research on malaria vaccine has been a continuous effort to eradicate the malaria infection, yet there is no vaccine against $P$. knowlesi malaria to date. Apical membrane antigen 1 (AMA1) is a unique surface protein of all apicomplexan parasites that plays a crucial role in parasite-host cell invasion and thus has been a long-standing malaria vaccine candidate. The selection of protective epitopes in silico has led to significant advances in the design of the vaccine. The present study aimed to employ bioinformatics tools to predict the potential immunogenic B- and T-cell epitopes in designing malaria vaccine targeting $P$. knowlesi AMA1 (PkAMA1). B-cell epitopes were predicted using four bioinformatics tools, i.e., BepiPred, ABCpred, BcePred, and IEDB servers whereas T-cell epitopes were predicted using two bioinformatics servers, i.e., NetMHCpan4.1 and NetMHCllpan-4.0 targeting human major histocompatibility complex (MHC) class I and class II molecules, respectively. The antigenicity of the selected epitopes computed by both B- and T-cell predictors were further analyzed using the VaxiJen server. The results demonstrated that PkAMA1 protein encompasses multi antigenic regions that have the potential for the development of multi-epitope vaccine. Two B- and T-cell epitopes consensus regions, i.e., NSGIRIDLGEDAEVGNSKYRIPAGKCP (codons 28-54) and KTHAASFVIAEDQNTSY RHPAVYDEKNKT (codons 122-150) at domain I (DI) of PkAMA1 were reported. Advancement of bioinformatics in characterization of the target protein may facilitate vaccine development especially in vaccine design which is costly and cumbersome process. Thus, comprehensive B-cell and T-cell epitope prediction of PkAMA1 offers a promising pipeline for the development and design of multi-epitope vaccine against $P$. knowlesi.
\end{abstract}

Keywords: Apical membrane antigen 1 (AMA1); Plasmodium knowlesi; bioinformatics; B-cell epitopes; T-cell epitopes.

\section{INTRODUCTION}

Malaria is a life-threatening disease caused by Plasmodium parasites that kills more than 400000 people worldwide every year. In 2019, an estimated 229 million new malaria infections and 409000 deaths were recorded (World Health Organization, 2020). Plasmodium knowlesi is classified as a zoonotic malaria parasite as the macaque monkeys serve as the reservoir host of this parasite species and transmission from animal to human is via anopheline mosquito. This species is now considered the fifth Plasmodium species that can cause human malaria, especially in forested areas of Southeast Asian countries (Chew et al.,
2012; Goh et al., 2013; Lee et al., 2015; Millar \& Cox-Singh, 2015; Zaw \& Lin, 2019; Cooper et al., 2020). Malaysia has reported zero indigenous cases for two consecutive years, 2018-2019. However, about 3213 cases of $P$. knowlesi were reported in 2019, which is only slightly lower than in the previous year, in which 4000 cases were reported (World Health Organization, 2020). Hence, research into the transmission control method such as vaccine development and antimalarial drugs is essential as an effective control strategy.

Even though many attempts have been made to develop an effective malaria vaccine, none has yet proven to be successful. This may be due to challenges in identifying the immunogenic antigens to be included as pivotal vaccine 
candidates. One such candidate is the apical membrane antigen 1 (AMA1) which is a Plasmodium membrane surface protein and long-standing malaria vaccine candidate. Plasmodium is an obligate intracellular parasite. The ability for host cell invasion determines the survivability of the parasite. Plasmodium AMA1 protein is expressed abundantly on the membrane surface of two infectives stages, i.e., sporozoites during human pre-erythrocytic cycle for hepatocytes penetration to establish human infection as well as merozoites for erythrocytes invasion during the last stages of pre-erythrocytic and erythrocytic cycles (Triglia et al., 2000; Silvie et al., 2004; Yang et al., 2017). Thus, making it a potential multistage malaria vaccine in humans. Generally, AMA1 is an integral membrane protein that consists of a pro-sequence, an ectodomain subdivided to the domain I (DI), domain II (DII), and domain III (DIII) stabilized by eight pairs of disulfide bonds from 16 invariant cysteine residues, followed by a transmembrane domain and a C-terminal cytoplasmic domain (Hodder et al., 1996). Nowadays, many successful anti-AMA1 vaccination studies have shown its ability to induce a humoral immune response in both animal and human clinical trials (Mahdi Abdel Hamid et al., 2011; Laurens et al., 2013; Sirima et al., 2017).

The identification and recognition of protein epitopes provide great interest in designing epitope-based vaccines and understanding antibody production by the immune system (Soria-Guerra et al., 2015). In general, B-cells recognize the epitope within the antigen and in turn protects against the pathogen by producing the antibodies. Besides that, major histocompatibility complex (MHC) class I and class II molecules present the peptides derived from the endocytosed protein of the pathogen and subsequently stimulate the cellular and humoral immunity against the pathogen. MHC class I-bounded peptide induces the helper T lymphocytes response, meanwhile, MHC class II-bounded peptide stimulates the cytotoxic T-cells $\left(\mathrm{CD} 8^{+}\right)$response (Nascimento \& Leite, 2012). Hence, over the past few decades, researchers have developed in silico prediction method that reduces the discovery process of the potential epitope of the antigen known as epitope mapping (Soria-Guerra et al., 2015; SanchezTrincado et al., 2017). In the present study, we described the computational analysis of antigenic linear B- and T-cell epitopes, which lie within the entire ectodomain of PkAMA1 protein using B- and T-cell prediction tools to seek potential multi-epitope vaccine candidates.

\section{MATERIALS AND METHODS}

\section{Protein sequence retrieval and physical and chemical properties assessment}

The amino acid sequence of AMA1 of $P$. knowlesi strain $\mathrm{H}$ was obtained from the National Center for Biotechnology Information (NCBI) protein database with the GenBank accession number: XM_002259303 in FASTA format to conduct bioinformatics assessment (Table 1). The entire ectodomain, i.e., DI-II-III of PkAMA1 was served as the template for the present structural and epitopes mapping study.

The Expert Protein Analysis System (ExPASy) ProtParam tool (https://web.expasy.org/protparam/) (Gasteiger et al., 2005) was used to characterize the various physical and chemical properties of PkAMA1 protein, which consists of a the total number of amino acids, molecular weight, theoretical isoelectric point ( $p l)$, amino acid composition, the total number of negatively (glutamic acid and aspartic acid) and positively (lysine and arginine) charged residues, atomic composition, instability index, aliphatic index, and grand average of hydropathicity (GRAVY).

\section{Prediction of B-cell epitopes}

Four bioinformatics servers were used for the prediction of B-cell epitopes, i.e., BepiPred-2.0 (http://www.cbs.dtu.dk/ services/BepiPred/) (Jespersen et al., 2017), Artificial neural network (ANN) based B-cell epitope prediction (ABCpred) (https://webs.iiitd.edu.in/raghava/abcpred/ABC_ submission.html) (Saha \& Raghava, 2006), B-cell epitope prediction (BcePred) (https://webs.iiitd.edu.in/raghava/ bcepred/bcepred_submission.html) (Saha \& Raghava, 2004), and The Immune Epitope Database (IEDB) (http://tools.iedb. org/bcell/) (Vita et al., 2019) (Table 1). Prediction in both BepiPred-2.0 and ABCpred servers were performed by loading the entire ectodomain of PkAMA1 protein sequence in a FASTA format as input data. In the Bepipred-2.0 prediction server, the 0.5 was default threshold for prediction. Meanwhile, in ABCpred server, a threshold was set at 0.8 and default window length of 16 amino acid residues was applied. Peptides with a higher score above threshold may have a greater probability of being considered as an epitope.

The BcePred is an online server that uses seven physicochemical parameters such as hydrophilicity (Parker et al., 1986), flexibility (Karplus \& Schulz, 1985), accessibility (Emini et al., 1985), turns (Pellequer et al., 1991), exposed surface (Janin \& Wodak, 1978), polarity (Ponnuswamy et al., 1980), and antigenic propensity (Kolaskar \& Tongaonkar, 1990) to predict linear B-cell epitopes (Saha \& Raghava, 2004). The amino acid residue segment above the threshold value is considered as predicted B-cell epitope and average propensity of the amino acid according to a particular scale were recorded. Meanwhile, the IEDB server predicts B-cell epitopes based on the following six parameters: Bepipred linear epitope prediction 2.0 (Jespersen et al., 2017), surface accessibility (Emini et al., 1985), antigenicity (Kolaskar \& Tongaonkar, 1990), beta-turn (Chou \& Fasman, 1978), flexibility (Karplus \& Schulz, 1985), and hydrophilicity (Parker et al., 1986). Results output presented in graphs and the average (or threshold), minimum, and maximum scores of each B-cell epitope parameters were recorded.

\section{Prediction of T-cell epitopes}

Two online servers, i.e., NetMHCpan-4.1 (http://www.cbs.dtu. $\mathrm{dk} /$ services/NetMHCpan-4.1/) and NetMHCllpan-4.0 (http:// www.cbs.dtu.dk/services/NetMHCllpan-4.0/) were used to predict T-cell epitopes within PkAMA1 protein binding to human MHC of class I and class II molecules, respectively (Reynisson et al., 2020) (Table 1). Ten most frequent human leukocyte antigen (HLA) alleles reference set for each of MHC class I and MHC class II molecules based on the previous study on $P$. vivax AMA1 (PvAMA1) were chosen for further analysis (Jahangiri et al., 2019). The sequences were given in plain format and the predicted peptide lengths in the NetMHCpan-4.1 and NetMHCIIpan-4.0 methods were nine and 15 amino acid residues, respectively. The findings are presented in percentile rank (\%Rank) of each peptide. In NetMHCpan-4.1, if the \%Rank is less than $0.5 \%$, a peptide is considered a strong binder, whereas if the \%Rank above $2 \%$, the peptide is considered a poor binder. In NetMHCllpan4.0 , strong binders are those with a \%Rank of less than $2 \%$ and poor binders are those with a \%Rank of more than $10 \%$.

\section{Prediction antigenicity of selected epitope peptide}

The B- and T-cell epitopes predicted by B- and T-cell predictors i.e., BepiPred-2.0, ABCpred, NetMHCpan-4.1 and NetMHCIIpan4.0 were subsequently screened for its antigenicity value using VaxiJen 2.0 server (http://www.ddg-pharmfac.net/ vaxijen/VaxiJen/VaxiJen.html). This server is routinely used for the prediction and classification of protective 
Table 1. Bioinformatics assessment servers used for characterization of Plasmodium knowlesi apical membrane antigen 1 (PkAMA1)

\begin{tabular}{|c|c|c|c|}
\hline Bioinformatics server & Description & Input/ Threshold & Website/ Reference \\
\hline $\begin{array}{l}\text { Expert Protein Analysis System } \\
\text { (ExPASy) ProtParam }\end{array}$ & $\begin{array}{l}\text { Computation tool for various } \\
\text { physical and chemical } \\
\text { parameters. }\end{array}$ & $\begin{array}{l}\text { GenBank accession number: } \\
\text { XM_002259303 } \\
\text { Ectodomain of PkAMA1 }\end{array}$ & $\begin{array}{l}\text { https://web.expasy.org/ } \\
\text { protparam/ } \\
\text { (Gasteiger et al., 2005) }\end{array}$ \\
\hline BepiPred-2.0 & $\begin{array}{l}\text { Sequence-based tool for the } \\
\text { prediction of continuous B-cell } \\
\text { epitopes based on random } \\
\text { forest algorithm trained on } \\
\text { epitopes derived from crystal } \\
\text { structures. }\end{array}$ & Default threshold: $>0.5$ & $\begin{array}{l}\text { http://www.cbs.dtu.dk/services/ } \\
\text { BepiPred } \\
\text { (Jespersen et al., 2017) }\end{array}$ \\
\hline $\begin{array}{l}\text { Artificial neural network (ANN) } \\
\text { based B-cell epitope prediction } \\
\text { (ABCpred) }\end{array}$ & $\begin{array}{l}\text { Sequence-based machine- } \\
\text { learning tool for the prediction of } \\
\text { continuous B-cell epitopes } \\
\text { based on neural networks (feed } \\
\text { forward and recurrent). }\end{array}$ & $\begin{array}{l}\text { Threshold: } 0.8 \\
\text { Default window length: } 16 \\
\text { amino acids }\end{array}$ & $\begin{array}{l}\text { https://webs.iiitd.edu.in/ } \\
\text { raghava/abcpred/ } \\
\text { ABC_submission.html } \\
\text { (Saha \& Raghava, 2006) }\end{array}$ \\
\hline $\begin{array}{l}\text { B-cell epitope prediction } \\
\text { (BcePred) }\end{array}$ & $\begin{array}{l}\text { B-cell epitope prediction } \\
\text { methods based on } \\
\text { physicochemical parameters. }\end{array}$ & $\begin{array}{l}\text { Default threshold: } \\
\text { Hydrophilicity: } 2 \\
\text { Flexibility: } 1.9 \\
\text { Accessibility: } 2 \\
\text { Turn: } 1.9 \\
\text { Exposed surface: } 2.4 \\
\text { Polarity: } 2.3 \\
\text { Antigenic propensity: } 1.8\end{array}$ & $\begin{array}{l}\text { https://webs.iiitd.edu.in/ } \\
\text { raghava/bcepred/ } \\
\text { bcepred_submission.html } \\
\text { (Saha \& Raghava, 2004) }\end{array}$ \\
\hline $\begin{array}{l}\text { The Immune Epitope Database } \\
\text { (IEDB) }\end{array}$ & $\begin{array}{l}\text { Antibody epitope prediction } \\
\text { using general basis amino acid } \\
\text { scales as parameters. }\end{array}$ & $\begin{array}{l}\text { Direct run for selected prediction } \\
\text { method, i.e., Bepipred } 2.0 \text {, } \\
\text { accessibility, antigenicity, beta- } \\
\text { turn, flexibility, and hydrophilicity. }\end{array}$ & $\begin{array}{l}\text { http://tools.iedb.org/bcell/ } \\
\text { (Vita et al., 2019) }\end{array}$ \\
\hline NetMHCpan-4.1 & $\begin{array}{l}\text { Prediction of binding of peptides } \\
\text { to any } \mathrm{MHC} \text { molecule class I } \\
\text { using ANNs. }\end{array}$ & Strong binders: \%Rank $\leq 0.5$ & $\begin{array}{l}\text { http://www.cbs.dtu.dk/services/ } \\
\text { NetMHCpan-4.1/ } \\
\text { (Reynisson et al., 2020) }\end{array}$ \\
\hline NetMHCIIpan-4.0 & $\begin{array}{l}\text { Prediction of binding of peptides } \\
\text { to any } \mathrm{MHC} \text { molecule class II } \\
\text { using ANNs. }\end{array}$ & Strong binders: \%Rank $\leq 2.0$ & $\begin{array}{l}\text { http://www.cbs.dtu.dk/services/ } \\
\text { NetMHCIIpan-4.0/ } \\
\text { (Reynisson et al., 2020) }\end{array}$ \\
\hline VaxiJen v2.0 & $\begin{array}{l}\text { Prediction of antigenicity of } \\
\text { protective antigen or non- } \\
\text { antigen server without the use } \\
\text { of sequence alignment. }\end{array}$ & $\begin{array}{l}\text { Antigenicity: } 0.5 \\
\text { Targeted model: Parasite }\end{array}$ & $\begin{array}{l}\text { http://www.ddg-pharmfac.net/ } \\
\text { vaxijen/VaxiJen/VaxiJen.html } \\
\text { (Doytchinova \& Flower, 2007) }\end{array}$ \\
\hline
\end{tabular}

Abbreviations: MHC, major histocompatibility complex; ANNs, Artificial neural networks (ANNs).

antigens and subunit vaccines based on the physicochemical properties of protein (Doytchinova \& Flower, 2007). Each of the selected epitopes were submitted in FASTA format and the parasite protein dataset was used to derive models for prediction of PkAMA1 protein antigenicity. The epitope that exceeds the default threshold of 0.5 antigenicity score was considered as a protective antigen. Meanwhile, peptide that had an antigenicity value that is less than the default threshold value (0.5) was excluded from the potential epitopes for vaccine design (Doytchinova \& Flower, 2007).

\section{RESULTS}

\section{Physical and chemical properties assessment}

The ExPASy ProtParam Tool is the tool for computing different physical and chemical properties of target protein. Generally, the entire ectodomain of PKAMA1 protein sequence ( 446 amino acids) was analyzed. The theoretical isoelectric point $(p l)$ and molecular weight of recombinant PkAMA1 protein are 5.98 and 51483.11 Dalton, respectively. The PkAMA1 aliphatic index was 66.05 , indicating the relative volume occupied by the aliphatic side chains (alanine, valine, isoleucine, and leucine). This result suggested that the AMA1 protein is thermally stable across a broad range of temperatures. Furthermore, the Grand Average of Hydropathy (GRAVY) that represents protein solubility was -0.754 , in which the negative GRAVY value indicates that the PkAMA1 protein is particularly hydrophilic. The instability index of 34.04 indicates that the protein is stable in the test tube, as a value of less than 40 is predicted to be stable.

\section{Prediction of B-cell epitopes}

The B-cell epitopes of PkAMA1 protein were predicted using four bioinformatics tools, i.e., BepiPred-2.0, ABCpred, BcePred, and IEDB prediction servers. The findings were displayed in the form of scored peptides (epitope sequence) using BepiPred-2.0 and ABCpred servers. Eight epitopes were predicted in the output of the prediction via the BepiPred2.0 server (Table 2). Meanwhile, a total of 12 non-overlapping $B$-cell epitopes were identified by the $A B C$ pred server, which 
is exceeding the threshold score of 0.8 (Table 3 ). The selected epitopes by BepiPred-2.0 and ABCpred servers were further analyzed via the VaxiJen 2.0 server and the antigenicity score of each epitope was presented together with the findings from the prediction tools. Peptides with antigenicity score at 0.5 default threshold for parasite were selected (Table 2 and Table 3). In both BepiPred-2.0 and ABCpred programs, the higher antigenicity score of the peptide represents the higher probability to be an epitope. The highest ABCpred score (0.94) was for epitope AEVGNSKYRIPAGKCP with a 0.7278 antigenicity score by VaxiJen 2.0. For BepiPrep-2.0, potential peptides above 0.5 threshold score were presented in various amino acid lengths.

BcePred and IEDB servers evaluate epitopes based on various physicochemical propensity scales of PkAMA1. The findings of each physicochemical property of BcePred and IEDB B-cell epitope predictions are presented in Figure 1 and Figure 2, respectively. The B-cell epitopes selected based on seven BcePred physicochemical predicting parameters were aligned to the position of PkAMA1 for ease of data interpretation (Figure 1). The average propensity of the amino acid according to a particular scale for BcePred prediction were as follow: hydrophilicity (1.9), flexibility (2.0), accessibility (1.9), turn (2.4), exposed surface (2.3), polarity (1.8), and antigenic propensity (1.9). Meanwhile, for IEDB server, the higher predicting score (above threshold) indicated a greater probability to be part of a potential epitope. The threshold or average, maximum, and minimum scores for each parameter were as follows: Bepipred linear epitope prediction $2.0(0.500,0.261,0.690)$, surface accessibility $(1.000,0.065,5.997)$, antigenicity $(1.008,0.852$, $1.231)$, beta-turn $(1.015,0.647,1.367)$, flexibility $(1.005,0.871$, $1.120)$, and hydrophilicity $(2.152,-4.543,6.757)$ (Figure 2$)$.

\section{Prediction of T-cell epitopes}

MHC-I and MHC-II binding epitopes data obtained from NetMHCpan-4.1 and NetMHCllpan-4.0 servers are listed in Table 4. The servers provide information including HLA alleles, predicted peptides, \%Rank, and binding level (strong or weak). Ten most frequent human $\mathrm{MHC}$ class I molecules included HLA-A01:01, HLA-A02:01, HLA-A03:01, HLA-A26:01, HLA-B07:02, HLA-B08:01, HLA-B15:01, HLA-B39:01, HLA-B40:01, and HLA-B58:01 alleles as well as 10 human MHC class II molecules included DRB1_0301, DRB1_0701, DRB3_0101, DRB5_0101, HLA-DPA10201-DPB10101, HLA-DPA10301-DPB10402, HLA-DPA10201-DPB11401, HLA-DQA10301-DQB10302, HLADQA10101-DQB10501, and HLA-DQA10501-DQB10301 alleles were analyzed. Only peptides that have a strong binding level were reported (Table 4). Overall, a total of 24 and 23 potential epitopes on the PkAMA1 protein were reported, which strongly bind to human MHC class I and MHC class II alleles, respectively. Results showed that the strongest binders belonged to allele HLA-B15:01 (RLKEGGFAF, 0.01 \%Rank, 0.9970 antigenicity) for $\mathrm{MHC}$ class I and allele DRB3_0101 (AMFCFKPDKNEKFDN, 0.03 \%Rank, 0.6140 antigenicity) for MHC class II.

\section{DISCUSSION}

Potential potent epitopes in antigen can be predicted using bioinformatics analysis, making vaccine production easier and faster. Analyzing the characteristics of PkAMA1 antigen using bioinformatics methods is a fundamental step in designing an efficient protein-based vaccine. The advancement of bioinformatic approaches provide the ability in identifying parasite immune-protective epitopes and incorporating them into malaria vaccine design. Several

Table 2. B-cell epitopes predicted by BepiPred-2.0 server on PkAMA1 protein with VaxiJen antigenicity score

\begin{tabular}{|c|c|c|c|}
\hline Position & Predicted epitope sequence & Length of amino acid & VaxiJen antigenicity score \\
\hline $5-19$ & ERSIRMSNPWKAFME & 15 & 0.6196 \\
\hline $36-51$ & GEDAEVGNSKYRIPAG & 16 & 0.8638 \\
\hline $130-138$ & IAEDQNTSY & 9 & 0.9030 \\
\hline $199-212$ & SNDWENKCPRKNLG & 14 & 0.6717 \\
\hline $284-301$ & LPVGAFNSDNFKSKGRGY & 18 & 1.6199 \\
\hline $338-378$ & PQEVDNEFPCSIYKDEIEREIKKQSRNMNLYSVDKERIVLP & 41 & 0.5140 \\
\hline $382-391$ & ISTDKESIKC & 10 & 0.6779 \\
\hline $411-420$ & VEKRAEIKEN & 10 & 1.3332 \\
\hline
\end{tabular}

Table 3. B-cell epitope predicted by ABCpred server on PkAMA1 protein with VaxiJen antigenicity score

\begin{tabular}{llc}
\hline Position & Predicted epitope sequence (16 amino acid residues) & Prediction score \\
\hline $1-16$ & GPIIERSIRMSNPWKA & 0.89 \\
$30-45$ & GIRIDLGEDAEVGNSK & 0.88 \\
$39-54$ & AEVGNSKYRIPAGKCP & 0.94 \\
$96-111$ & PITIANLKERYKENAD & 0.7609 \\
$135-150$ & NTSYRHPAVYDEKNKT & 0.80 \\
$199-214$ & SNDWENKCPRKNLGNA & 0.92 \\
$217-232$ & GLWVDGNCEEIPYVNE & 0.82 \\
$248-263$ & ASASDQPRQYEEELTD & 0.87 \\
$297-312$ & KGRGYNWANFDSVNNK & 0.8793 \\
$311-326$ & NKCYIFNTKPTCLIND & 0.89 \\
$321-336$ & TCLINDKNFFATTALS & 0.89 \\
$410-425$ & CVEKRAEIKENNEVII & 0.81 \\
\hline
\end{tabular}




\begin{tabular}{|c|c|}
\hline Domain & \\
\hline & \\
\hline hilicity & LERAHNSGIRIDLGEDAEVGNSKYRIPAGKCPVFGKGIVIENSNVSFLTPVATGAQRL \\
\hline bility & $D L G E D A E V G N S K Y R I P A G K C P V F G K G I V I E N S N V S F L T P V A T G A Q R L$ \\
\hline ( & 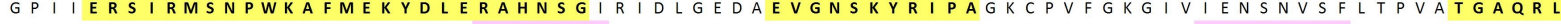 \\
\hline Turns & G p l \\
\hline Exposed su & GP \\
\hline Polarity & GPIIERSIRMSNPWKAFMEKYDLERAHNSG|RIDLGEDAEVGNSKYRIPAGKCPVFGKGIVIENSNVSFLTPVATGAQRL \\
\hline \multirow[t]{2}{*}{ Antigenic propensity } & GPIIERSIRMSNPWKAFMEKYDLERAHNSGIRIDLGEDAEVGNSKYRIPAGKCPVFGKGIVIENSNVSFLTPVATGAQRL \\
\hline & $\begin{array}{l}1 \\
9\end{array}$ \\
\hline Aminoa & 12345678901234567890123456789012345678901234567890123456789012345678901234567890 \\
\hline Hydrophilicity & KEGGFAFPNADDHISPITIANLKERYKENADLMKLNDIALCKTHAASFVIAEDQNTSYRHPAVYDEKNKTCYMLYLSAQE \\
\hline Flexibility & KEGGFAFPNADDHISPITIANLKERYKENADLMKLNDIALCKTHAASFVIAEDQNTSYRHPAVYDEKNKTCYMLYLSAQE \\
\hline Accessibility & KEGGFAFPNADDHISPITIANLKERYKENADLMKLNDIALCKTHAASFVIAEDQNTSYRHPAVYDEKNKTCYMLYLSAQE \\
\hline Turns & KEGGFAFPNADDHISPITIANLKERYKENADLMKLNDIALCKTHAASFVIAEDQNTSYRHPAVYDEKNKTCYMLYLSAQE \\
\hline Expose & KEGGFAFPNADDHISPITIANLKERYKENADLMKLNDIALCKTHAASFVIAEDQNTSYRHPAVYDEKNKTCYMLYLSAQE \\
\hline Polarity & KEGGFAFPNADDHISPITIANLKERYKENADLMKLNDIALCKTHAASFVIAEDQNTSYRHPAVYDEKNKTCYMLYLSAQE \\
\hline \multirow[t]{2}{*}{ Antigen } & KEGGFAFPNADDHISPITIANLKERYKENADLMKLNDIALCKTHAASFVIAEDQNTSYRHPAVYDEKNKTCYMLYLSAQE \\
\hline & 1111111111 , \\
\hline Domain & 6666666667777777777888888888899999999990000000000111111111111222222222233333333334 \\
\hline sition & 123456789012345678901234567890123456789012345678901234567890123456789012345678900 \\
\hline Hydrophilici & NMGPRYCSPDSQNKDAMFCFKPDKNEKFDNLVYLSKNVSNDWENKCPRKNLGNAKFGLWVDGNCEEIPYVNEVEARSLRE \\
\hline Flexibility & NMGPRYCSPDSQNKDAMFCFKPDKNEKFDNLVYLSKNVSNDWENKCPRKNLGNAKFGLWVDGNCEEIPYVNEVEARSLRE \\
\hline Accessin & NMGPRYCSPDSQNKDAMFCFKPDKNEKFDNLVYLSKNVSNDWENKCPRKNLGNAKFGLWVDGNCEEIPYVNEVEARSLRE \\
\hline Turns & NMGPRYCSPDSQNKDAMFCFKPDKNEKFDNLVYLSKNVSNDWENKCPRKNLGNAKFGLWVDGNCEEIPYVNEVEARSLRE \\
\hline & NMGPRYCSPDSQNKDAMFCFKPDKNEKFDNLVYLSKNVSNDWENKCPRKNLGNAKFGLWVDGNCEEIPYVNEVEARSLRE \\
\hline Polarity & NMGPRYCSPDSQNKDAMFCFKPDKNEKFDNLVYLSKNVSNDWENKCPRKNLGNAKFGLWVDGNCEEIPYVNEVEARSLRE \\
\hline \multirow[t]{2}{*}{ Antigenic propensity } & NMGPRYCSPDSQNKDAMFCFKPDKNEKFDNLVYLSKNVSNDWENKCPRKNLGNAKFGLWVDGNCEEIPYVNEVEARSLRE \\
\hline & \\
\hline Domain & 4444444445555555555666666666677777777777888888888899999999990000000000111111111112 \\
\hline & 12345678901234567890123456789012345667890123456789012345678901234 \\
\hline Hy & CNRIVFEASASDQPRQYEEELTDYEKI QEGFRQNNRDMIKSAFLPVGAFNSDNFKSKGRGYNWANFDSVNNKCYIFNTKP \\
\hline Flexit & CNRIVFEASASDQPRQYEEELTDYEKIQEGFRQNNRDMIKSAFLPVGAFNSDNFKSKGRGYNWANFDSVNNKCYIFNTKP \\
\hline & VFEASASDQPRQYEEELTDYEKIQEGFRQNNRDMIKSAFLPVGAFNSDNFKSKGRGYNWANFDSVN \\
\hline Tur & CNRIVFEASASDQPRQYEEELTDYEKIQEGFRQNNRDMIKSAFLPVGAFNSDNFKSKGRGYNWANFDSVNNKCYIFNTKP \\
\hline Expc & CNRIVFEASASDQPRQYEEELTDYEKIQEGFRQNNRDMIKSAFLPVGAFNSDNFKSKGRGYNWANFDSVNNKCYIFNTKP \\
\hline Polari & CNRIVFEASASDQPRQYEEELTDYEKIQEGFRQNNRDMIKSAFLPVGAFNSDNFKSKGRGYNW, \\
\hline \multirow[t]{2}{*}{ Antigenic propensity } & CNRIVFEASASDQPRQYEEELTDYEKIQEGFRQNNRDMIKSAFLPVGAFNSDNFKSKGRGYNWANFDSVNNKCYIFNTKP \\
\hline & \\
\hline Do & 22222222233333333333344444444445555555555666666666677777777778888888 \\
\hline on & 1234567890123456789012345678901234567890123456789012345678901233456789012 \\
\hline Hy & TCLINDKNFFATTALSHPQEVDNEFPCSIYKDEIEREIKKQSRNMNLYSVDKERIVLPRIFIS \\
\hline & LSHPQEVDNEFPCSIYKDEIEREIKKQSSRNMNLYSVDKERIVLP \\
\hline & TCLINDKNFFATTALSHPQEVDNEFPCSIYKDEIEREIKKQSRNMNLYSVDKERIVLPRIFIST \\
\hline Turns & TCLINDKNFFATTALSHPQEVDNEFPCSIYKDEIEREIKKQSRNMNLYSVDKERIVLPRIFIST \\
\hline & TCLINDKNFFATTALSHPQEVDNEFPCSIYKDEIEREIKKQSRNMNLYSVDKERIVLPR I \\
\hline Polarity & TCLINDKNFFATTALSHPQEVDNEFPCSIYKDEIEREIKKQSRNMNLYSVDKERIVLPRIFISTDKESIKCPCEP \\
\hline \multirow[t]{2}{*}{ Antigenic propensity } & TCLINDKNFFATTALSHPQEVDNEFPCSIYKDEIEREIKKQSRNMNLYSVDKERIVLPRIFISTDKESIKCPCEPEHISN \\
\hline & \\
\hline Do & 33333344444444 \\
\hline & 1234567890123456789012345678901234567890123456 \\
\hline & STCNFYVCNCVEKRAEIKENNEV I IKEEFKEDYENPDGKHKKKMLL \\
\hline & NCVEKRAE IKENNEVII KEEFKEDYENPDGKHKKKML \\
\hline Acce & STCNFYVCNCVEKRAEIKENNEV \\
\hline Turns & $S T C N F Y V C N C V E K R A E$ I KENNEVI I KEEFKEDYENPDGKHKKKMLL \\
\hline Exp & L L \\
\hline Po & NFYVCNCVEKRAE IKENNEVI IKEEFKEDVENPDGKHKKKMLL \\
\hline & \\
\hline
\end{tabular}

Figure 1. B-cell epitopes predicted on PkAMA1 protein using BcePred based on seven physicochemical predicting parameters, i.e., hydrophilicity, flexibility, accessibility, turns, exposed surface, polarity, and antigenic propensity.

previous studies have performed reverse vaccinology research, using bioinformatics tools in designing epitopebased vaccine (Singh et al., 2010; Durojaye et al., 2018; Motamedpour et al., 2020; Zawawi et al., 2020). A subunit vaccine based on predicted epitopes elicits a strong immune response by inducing humoral and cell-mediated immunity against the disease. Development of malaria vaccine is still in continuous research despite emergence of promising vaccine candidates. Genetic variation within 5188 proteinencoding $P$. knowlesi genes in a single strain, as well as specific protein expression at each stage of the complex malaria life cycle, pose challenges in developing a vaccine that can effectively provide protective immunity against malaria disease (Pain et al., 2008).
Various bioinformatics tools were applied in this study to obtain more information on the characteristics of the PKAMA1 protein, which could be useful in vaccine design. Since this is the first study of PkAMA1 prediction of B-cell and T-cell epitopes and some other characteristics, therefore we have only limited reference data to compare our results. There was only one study reported on the analysis of AMA1 in identifying potential epitopes for $P$. vivax vaccine design (Jahangiri et al., 2019).

Generally, immunogenic ectodomain of PkAMA1 is subdivided into three immunogenic domains, i.e., domain I (DI: 206 amino acids with residue positions of 1-206), domain II (DII: 138 amino acids with residue positions of 207-344), and domain III (DIII: 102 amino acids with residue 
(A) Bepipred linear epitope prediction 2.0

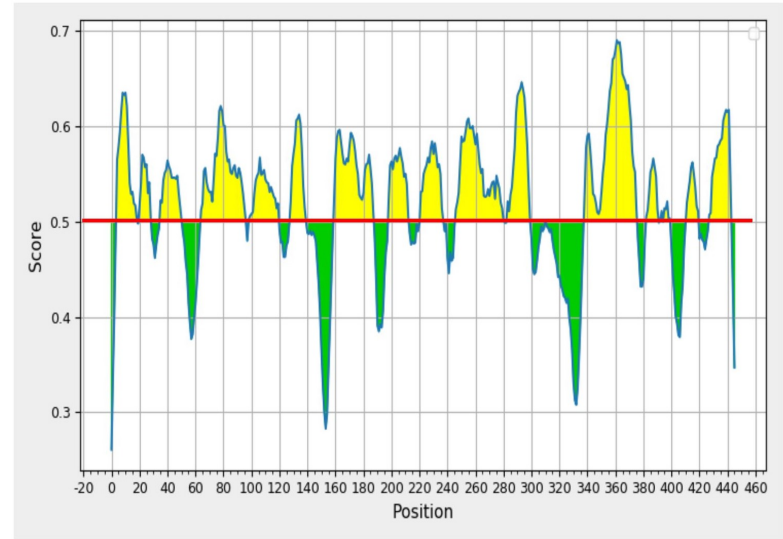

(C) Antigenicity

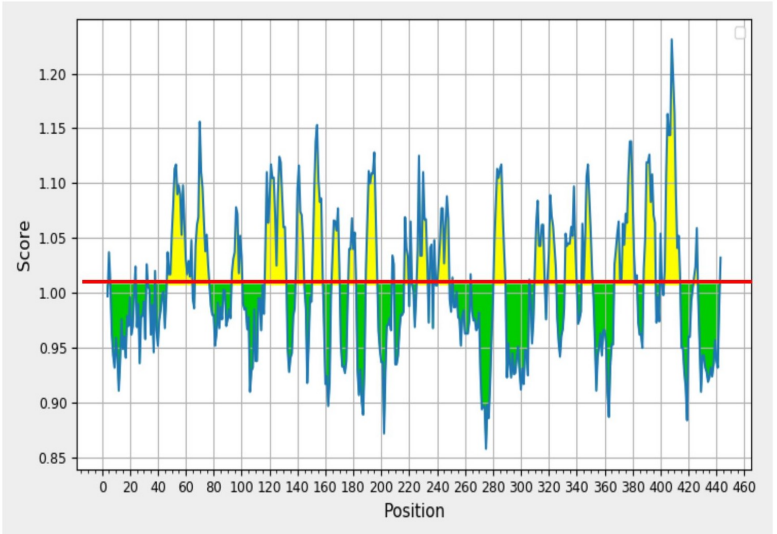

(E) Flexibility

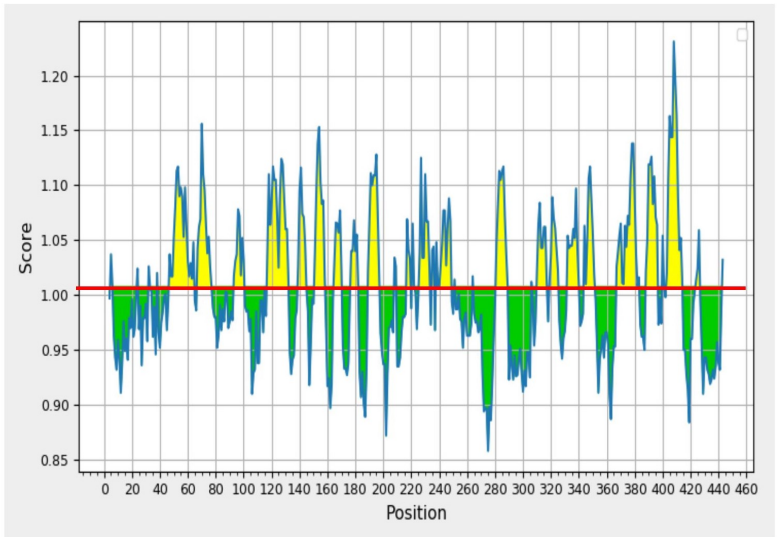

(B) Surface accessibility

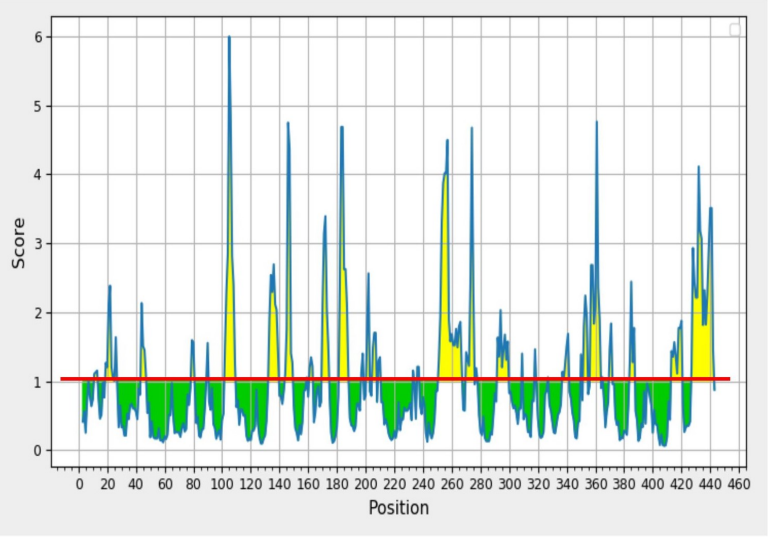

(D) Beta-turn

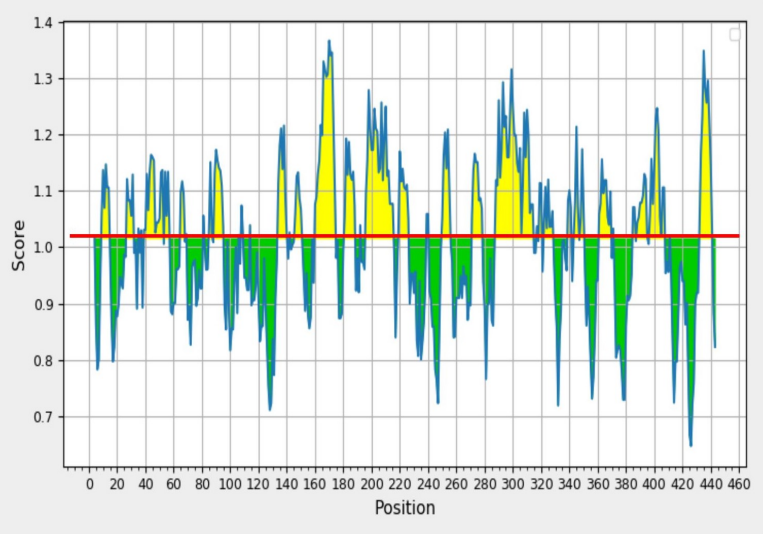

(F) Hydrophilicity

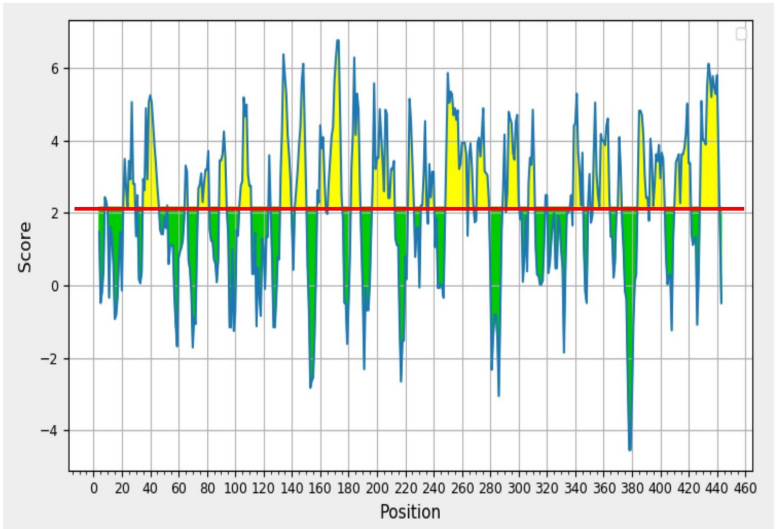

Figure 2. The B-cell epitope prediction using Immune Epitope Database (IEDB) server based on six parameters. (A) Bepipred linear epitope prediction 2.0, (B) accessibility, (C) antigenicity, (D) beta-turn, (E) flexibility, and (F) hydrophilicity. The score of each residue is plotted on a $\mathrm{Y}$-axes and the $\mathrm{X}$-axes correspond to the residue positions of PkAMA1 protein sequence. The larger score for the residues is interpreted as that the residue with a higher probability to be part of a potential epitope (above the threshold score).

positions of 345-446) (Haron et al., 2020). The predicted B-cell epitopes using BepiPred-2.0 and ABCpred as well as T-cell epitopes using NetMHCpan-4.1 and NetMHCllpan-4.0 were aligned for immunogenic and antigenicity epitopes mapping (Figure 3 ). The ability of these bioinformatics tools in identifying antigenic linear B-cell epitopes and T-cell epitopes within the entire ectodomain of PkAMA1 is beneficial for the development of a synthetic epitope-based vaccine. Theoretically, the multi-epitope vaccine elicits immune responses based on short immunogenic sequences instead of large protein, which is typically used for recombinant vaccine technology.

BepiPred-2.0, ABCpred, BcePred, and IEDB prediction server are widely used as linear B-cell epitope predictors 


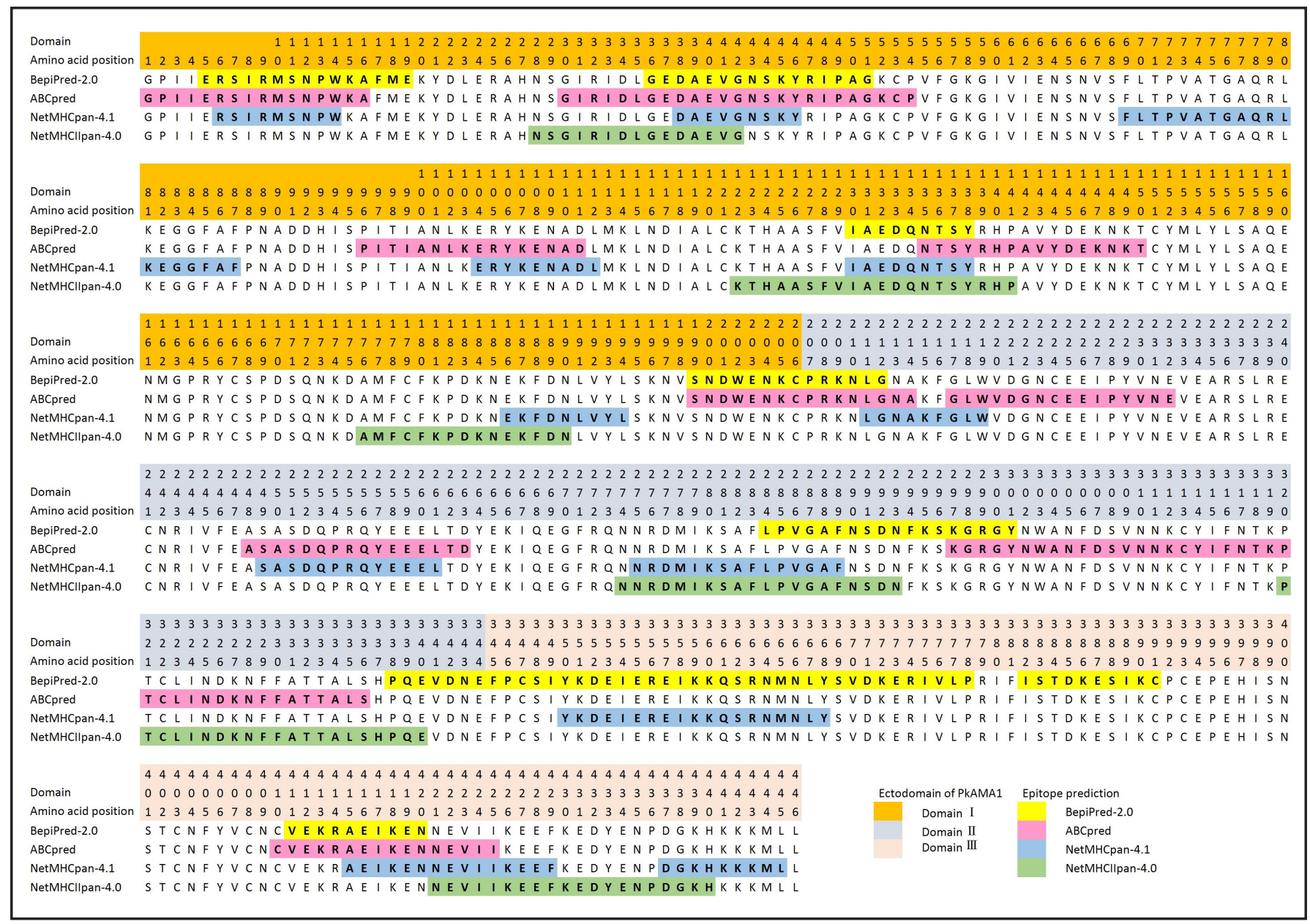

Figure 3. Analysis of B and T-cell epitopes predicted four bioinformatics tools i.e., BepiPred-2.0, ABCpred, NetMHCpan-4.1, and NetMHCllpan-4.0 servers.

(Vita et al., 2019; Galanis et al., 2021). The latest version of BepiPred-2.0 was developed in 2017, based on random forests algorithm trained on B-cell epitopes derived from protein structures of antigen-antibody complexes (Jespersen et al., 2017). Epitope data obtained from crystal structures are considered as a higher quality that significantly enhanced the predictive power. This method performs better than other available methods for sequence-based epitope prediction both on epitope data derived from threedimensional structures and on a wide set of linear epitopes downloaded from the IEDB database, making it a reliable and effective tool for predicting linear B-cell epitopes (Sanchez-Trincado et al., 2017; Galanis et al., 2019, Galanis et al., 2021). The best performance B-cell epitope predictor is BepiPred as it achieved the highest Matthews correlation coefficient value that measures the overall accuracy of the prediction (Galanis et al., 2019). A highly antigenic B-cell epitope proven to be serologically reactive during natural infection was discovered within the PvAMA1 vaccine candidate using a BepiPred server (Bueno et al., 2011). $A B C p r e d$ predicts continuous epitopes for protein sequences using a recurrent neural network. The users can choose their expected epitope length as the window size used for prediction includes $10,12,14,16,18$ and 20 . The 16 amino acid residues window size achieves the highest accuracy of 65.93\% (Saha \& Raghava, 2006). Two high antigenicity B-cell epitopes (>1 antigenicity score) were predicted via BepiPrep2.0 server, i.e., LPVGAFNSDNFKSKGRGY located within DII (antigenicity score of 1.6199) and VEKRAEIKEN located within
DIII (antigenicity score of 1.3332). The VEKRAEIKEN, which is also a partial sequence of an epitope, i.e., CVEKRAEIKENNEVII (codons 410-425 and antigenicity score of 0.9352) obtained via $A B C$ pred prediction as well as BcePred prediction on accessibility and polarity propensity scales (Figure 1 ).

BcePred and IEDB prediction methods are bioinformatics tools that are currently used in this study to predict linear Bcell epitopes based on physicochemical propensity scales of amino acid properties. For BcePred prediction, regions of epitopes that fulfil the protein characterization based on its seven propensity scales, i.e., hydrophilicity, flexibility, accessibility, turns, exposed surface, polarity, and antigenic propensity have potential to be included in vaccine design as they can be recognized by antibodies. It is important to classify potential regions and non-significant regions of each scale. Successful identification and classification of antigenic protein such as surface accessibility, antigenicity, beta-turn, flexibility, and hydrophilicity regions are of importance in the selection of suitable B-cell epitopes design (Zobayer et al., 2019). The hydrophilic region is crucial for inducing host immune response, while beta-turn region is an element in the protein secondary structure, which is important for the epitope vaccine design (Zobayer et al., 2019). Based on each of the physicochemical properties, the accuracy of BcePred prediction varies from $52.92 \%$ to $57.53 \%$ (Saha \& Raghava, 2004). The accuracy of prediction enhanced by evaluation of the combination of two or more parameters. The highest accuracy of $58.70 \%$ on a data set was achieved in a combination of four amino acid properties, i.e., 
Table 4. Prediction of human major MHC class I and MHC class II binding epitopes on PkAMA1 protein using NetMHCpan-4.1 and NetMHCIIpan-4.0 servers with VaxiJen antigenicity score

\begin{tabular}{|c|c|c|c|c|}
\hline Allele (number, $n$ ) & Position & Predicted epitope sequence & \%Rank & VaxiJen antigenicity score \\
\hline \multicolumn{5}{|c|}{ (A) NetMHCpan-4.1: Human MHC class I binding epitope prediction (SB: <0.5 \%Rank) } \\
\hline \multirow[t]{3}{*}{ HLA-A01:01 (n=3) } & $130-138$ & IAEDQNTSY & 0.06 & 0.9030 \\
\hline & $38-46$ & DAEVGNSKY & 0.20 & 1.0032 \\
\hline & $249-257$ & SASDQPRQY & 0.23 & 0.5342 \\
\hline HLA-A02:01 $(n=1)$ & $69-77$ & FLTPVATGA & 0.33 & 1.1651 \\
\hline \multirow[t]{3}{*}{ HLA-A26:01 (n=3) } & $249-257$ & SASDQPRQY & 0.21 & 0.5342 \\
\hline & $357-365$ & EIKKQSRNM & 0.29 & 0.8812 \\
\hline & $281-289$ & SAFLPVGAF & 0.31 & 1.2073 \\
\hline HLA-B07:02 (n=1) & $253-261$ & QPRQYEEEL & 0.05 & 1.2590 \\
\hline \multirow[t]{3}{*}{ HLA-B08:01 $(n=3)$} & $437-445$ & DGKHKKKML & 0.12 & 1.2331 \\
\hline & $253-261$ & QPRQYEEEL & 0.23 & 1.2590 \\
\hline & $357-365$ & EIKKQSRNM & 0.37 & 0.8812 \\
\hline \multirow[t]{5}{*}{ HLA-B15:01 ( $n=5)$} & $79-87$ & RLKEGGFAF & 0.01 & 0.9970 \\
\hline & $360-368$ & KQSRNMNLY & 0.08 & 0.7704 \\
\hline & $77-85$ & AQRLKEGGF & 0.29 & 1.8973 \\
\hline & $281-289$ & SAFLPVGAF & 0.37 & 1.2073 \\
\hline & $249-257$ & SASDQPRQY & 0.44 & 0.5342 \\
\hline \multirow[t]{4}{*}{ HLA-B39:01 $(n=4)$} & $275-283$ & NRDMIKSAF & 0.13 & 1.1542 \\
\hline & $186-194$ & EKFDNLVYL & 1.15 & 0.7741 \\
\hline & $350-358$ & YKDEIEREI & 0.23 & 0.7608 \\
\hline & $104-112$ & ERYKENADL & 0.26 & 0.8829 \\
\hline \multirow[t]{2}{*}{ HLA-B40:01 $(n=2)$} & $415-423$ & AEIKENNEV & 0.10 & 0.9380 \\
\hline & $421-429$ & NEVIIKEEF & 0.42 & 0.8750 \\
\hline \multirow[t]{2}{*}{ HLA-B58:01 $(n=2)$} & $6-14$ & RSIRMSNPW & 0.05 & 0.5101 \\
\hline & $211-219$ & LGNAKFGLW & 0.50 & 1.0246 \\
\hline \multicolumn{5}{|c|}{ (B) NetMHCllpan-4.0: Human MHC class II binding epitope prediction (SB: $\leq 2 \%$ Rank) } \\
\hline \multirow[t]{5}{*}{ DRB1_0301 $(n=5)$} & $127-141$ & SFVIAEDQNTSYRHP & 0.32 & 0.7607 \\
\hline & $28-42$ & NSGIRIDLGEDAEVG & 0.65 & 0.7932 \\
\hline & $176-190$ & AMFCFKPDKNEKFDN & 1.22 & 0.6140 \\
\hline & $422-436$ & EVIIKEEFKEDYENP & 1.25 & 1.0296 \\
\hline & $320-334$ & PTCLINDKNFFATTA & 1.95 & 0.9884 \\
\hline DRB1_0701 $(n=1)$ & $326-340$ & DKNFFATTALSHPQE & 0.22 & 0.9362 \\
\hline \multirow[t]{4}{*}{ DRB3_0101 $(n=4)$} & $176-190$ & AMFCFKPDKNEKFDN & 0.03 & 0.6140 \\
\hline & $127-141$ & SFVIAEDQNTSYRHP & 0.27 & 0.7607 \\
\hline & $426-440$ & KEEFKEDYENPDGKH & 0.64 & 0.5879 \\
\hline & $28-42$ & NSGIRIDLGEDAEVG & 0.65 & 0.7932 \\
\hline \multirow[t]{2}{*}{ DRB5_0101 $(n=2)$} & $326-340$ & DKNFFATTALSHPQE & 1.04 & 0.9362 \\
\hline & $279-293$ & IKSAFLPVGAFNSDN & 1.61 & 0.9234 \\
\hline \multirow[t]{3}{*}{ HLA-DPA10201-DPB10101 $(n=3)$} & $421-435$ & NEVIIKEEFKEDYEN & 0.22 & 1.0060 \\
\hline & $274-288$ & NNRDMIKSAFLPVGA & 0.48 & 0.8665 \\
\hline & $326-340$ & DKNFFATTALSHPQE & 0.54 & 0.9362 \\
\hline \multirow[t]{3}{*}{ HLA-DPA10301-DPB10402 (n=3) } & $421-435$ & NEVIIKEEFKEDYEN & 0.22 & 1.0060 \\
\hline & $274-288$ & NNRDMIKSAFLPVGA & 0.37 & 0.8665 \\
\hline & $326-340$ & DKNFFATTALSHPQE & 0.49 & 0.9362 \\
\hline HLA-DPA10201-DPB11401 $(n=1)$ & $326-340$ & DKNFFATTALSHPQE & 0.22 & 0.9362 \\
\hline \multirow[t]{3}{*}{ HLA-DQA10301-DQB10302 $(n=3)$} & $122-136$ & KTHAASFVIAEDQNT & 0.95 & 0.7835 \\
\hline & $426-440$ & KEEFKEDYENPDGKH & 1.21 & 0.5879 \\
\hline & $326-340$ & DKNFFATTALSHPQE & 1.30 & 0.9362 \\
\hline HLA-DQA10101-DQB10501 (n=1) & $122-136$ & KTHAASFVIAEDQNT & 1.70 & 0.7835 \\
\hline
\end{tabular}

Major histocompatibility complex $(\mathrm{MHC}) ; \mathrm{HLA}=$ human leucocyte antigen; \%Rank = percentile rank; SB = strong binder. 
hydrophilicity, flexibility, polarity, and surface accessibility in B-cell epitopes prediction (Saha \& Raghava, 2004; Galanis et al., 2019; Galanis et al., 2021). However, a previous study found that the prediction of linear B-cell epitopes based on amino acid scales has a poor performance, thus other B-cell epitope prediction methods such as BepiPred-2.0 and ABCpred were preferred (Sanchez-Trincado et al., 2017).

The emergence of bioinformatics tools, i.e., NetMHCpan4.1 and NetMHCllpan-4.0 have enabled the prediction of MHC of class I and class II binding epitopes, respectively (Reynisson et al., 2020). MHC class II proteins in humans are expressed on the surface of antigen presenting cells such as macrophages, dendritic cells, and B lymphocytes. They can bind to peptides with a length of 13 to 18 amino acids (Sanchez-Trincado et al., 2017). Meanwhile, the complex of immunogenic peptide-MHC class $I$ is expressed on nucleated cells, where it is recognized by cytotoxic T-cells and consequently triggers the immune response. Generally, $\mathrm{MHC}$ class I bound peptides have eight to 10 amino acid residues (Sanchez-Trincado et al., 2017). The binding affinity of peptide antigen to one allele and another differs, allowing the driving immune responses to increase or decrease. According to the corresponding \%Rank, all listed peptides, which can bind strongly to $\mathrm{MHC}$ class I and $\mathrm{MHC}$ class II molecules are potential immunodominant T-cell epitopes and useful markers for further $P$. knowlesi vaccine development. Protein antigenicity makes that protein detectable via the immune system. The antigenicity of each epitope is further assessed with VaxiJen at 0.5 threshold for parasites dataset. VaxiJen server is an immunoinformatic strategy that integrate both immunology and vaccinology studies to distinguish immunogens and non-immunogens based on their similarity to other existing immune-protective antigen. The accuracy of the server in predicting immunogenicity of the antigens within a parasite range from $78 \%$ to $97 \%$ and the peptide with the higher immunogenicity score is thought to have a higher probability of being protective (Zaharieva et al., 2017).

Among the ten MHC class I and MHC class II alleles chosen for this study, only HLA-A03:01 and HLA-DQA10501DQB10301, respectively did not score any strong binding epitope. Most of the MHC strong binders belonged to HLA-B15:01 allele (MHC class I, $n=5$ ) and DRB1_0301 allele ( $\mathrm{MHC}$ class II, $n=5$ ). Two MHC class I strong binders, i.e., RLKEGGFAF and RSIRMSNPW are hit to the similar epitopes of PVAMA1 study (RLKDGGFAF and RSTRMSNPW), which also showed that strong binders belonged to similar allele (Jahangiri et al., 2019). However, they found that the strongest binding epitopes of PVAMA1 for MHC class II belonged to HLA-DPA10201-DPB11401 allele, while in our study, the strongest binding epitope (AMFCKPDKNEKFDN) belonged to DRB3_0101. All the MHC class II strong binders hit at least twice and even up to six times, i.e., DKNFFATTALSHPQE (codons 326-340 of DII with prediction scores ranged from 0.22 to 1.30 with antigenicity score of 0.9384 ) and a partial peptide sequence, i.e., PTCLINDKNFFATTA (codons 320-334 of DII with antigenicity score of 0.9884 ) amongst 10 tested MHC class II alleles. Interestingly, similar epitope (DKNFIATTALSHPQEV) is the strongest binder for PVAMA1 belonged to HLADPA10201-DPB11401 and also DRB1_0701 alleles (Jahangiri et al., 2019). The TCLINDKNFFATTALS (codons 321-336 with antigenicity score of 0.9584 ) is also a ABCpred-predicted $B$-cell epitope candidate in the present study.

Mapping of all potential B- and T-cell epitopes obtained from seven prediction tools used in the present study found two significant immunogenic epitope regions, i.e., NSGIRIDLGEDAEVGNSKYRIPAGKCP (codons 28-54) and
KTHAASFVIAEDQNTSYRHPAVYDEKNKT (codons 122-150) at domain I (DI) of PkAMA1 which reported with short consensus sequence of DAEVG and NTSY, respectively. Interestingly, peptides located in DI of PVAMA1 (EVENAKYRIPAGRCPVFGKG) and P. falciparum AMA1 (PfAMA1) (DI, DAEVAGTQYRLPSGKCPVFG; DI-II, VVDNWEKVCPRKNLQNAKFG, similar to codons 198-217 in PKAMA1; and DII, MIKSAFLPTGAFKADRYKSH, similar to codons 278-297 in PkAMA1) were critical erythrocyte binding conserved peptides, which are previously reported B-cell epitopes that was capable to induce antibodies to block merozoite invasion into host cell erythrocytes and development (Urquiza et al., 2000; Arévalo-Pinzón et al., 2017). In term of B-cell epitope prediction servers used in the study, the potential epitopes were hit to almost similar regions despite different predicting parameters from each of server used. For instance, ERSIRMSNPWKAFME (codons 5-19 with antigenicity score of 0.6196), GEDAEVGNSKYRIPAG (codons 36-51 with antigenicity score of 0.8638), SNDWENKCPRKNLG (codons 199-212 with antigenicity score of 0.6717), and VEKRAEIKEN (codons 411-420 with antigenicity score of 1.3332). Meanwhile, for T-cell prediction, there were some similar hit regions on $\mathrm{MHC}$ class I and MHC class II alleles, such as DAEVG (codons 38-42), IAEDQNTSY (codons 130-138, also BepiPred-2.0 B-cell epitope), EKFDN (codons 186-190), NRDMIKSAFLPVGAF (codons 275-289), and NEVIIKEEF (codons 421-429).

Peptides (epitopes) with the ability to be recognized by HLA-DRB1 alleles are preferred vaccine candidates because of their ability to elicit an immune response that generates protection (Stern \& Calvo-Calle, 2009; López et al., 2018). Depending on the peptides bound to MHC receptors, T-cells can trigger stronger immune responses after recognizing an antigen processing cell (Blum et al., 2013). A previous study reported that in silico prediction of $P$. vivax rhoptry neck protein 2 precursor (RON2) epitope by NetMHCpan program successfully induced a naturally-acquired T-cell immune response in $P$. vivax-exposed individuals (López et al., 2018). RON2 is another essential apicomplexan protein that will bind to AMA1 to facilitate the formation of moving junction to drive the parasite binding and invasion abilities. The feasibility of multi-epitope vaccine development is supported by the cytokines produced by volunteers immunized with irradiated sporozoite able to bind to a wide range of parasite antigens rather than focusing on specific proteins or epitopes (Doolan et al., 2003). The advancement in bioinformatics tools not only makes multi-epitope vaccine design and development feasible, but also enables a cross-species protection, especially for those antigens possessed an abundance of B- and T-cell epitopes with high immunogenicity and antigenicity such as Plasmodium AMA1 protein.

\section{CONCLUSION}

The results presented in this study illustrate a comprehensive analysis of PkAMA1 antigens using bioinformatics tools. To the best of our knowledge, this is the first study of the comprehensive $B$ - and T-cell epitope prediction and analysis of the physicochemical characteristics of PkAMA1 using various reliable bioinformatics tools. All data suggest that PkAMA1 protein contains potential epitopes scattered along the different domains, and thus could be used for vaccine development against $P$. knowlesi malaria. However, there is a need of further empirical validation to prove this in silico work. 


\section{ACKNOWLEDGEMENTS}

This study was supported by the Ministry of Higher Education Malaysia under the Fundamental Research Grant Scheme (FRGS) (Project no. FRGS/1/2015/SKK12/UNISZA/02/1).

\section{Conflict of interests}

The authors declare that they have no conflict of interests.

\section{REFERENCES}

Arévalo-Pinzón, G., Bermúdez, M., Hernández, D., Curtidor, H. \& Patarroyo, M.A. (2017). Plasmodium vivax ligand-receptor interaction: PvAMA-1 domain I contains the minimal regions for specific interaction with $C D 71+$ reticulocytes. Scientific Reports 7: 9616. https://doi.org/10.1038/s41598017-10025-6

Blum, J.S., Wearsch, P.A. \& Cresswell, P. (2013). Pathways of antigen processing. Annual Review of Immunology 31: 443473. https://doi.org/10.1146/annurev-immunol-032712095910

Bueno, L.L., Lobo, F.P., Morais, C.G., Mourão, L.C., de Ávila, R.A., Soares, I.S., Fontes, C.J., Lacerda, M.V., Chavez Olórtegui, C. \& Bartholomeu, D.C. (2011). Identification of a highly antigenic linear B cell epitope within Plasmodium vivax apical membrane antigen 1 (AMA-1). PLoS One 6: e21289. https://doi.org/10.1371/journal.pone.0021289

Chew, C.H., Lim, Y.A., Lee, P.C., Mahmud, R. \& Chua, K.H. (2012). Hexaplex PCR detection system for identification of five human Plasmodium species with an internal control. Journal of Clinical Microbiology 50: 4012-4019. https://doi.org/ 10.1128/JCM.06454-11

Chou, P.Y. \& Fasman, G.D. (1978). Prediction of the secondary structure of proteins from their amino acid sequence. Advances in Enzymology and Related Areas of Molecular Biology 47: 45-148. https://doi.org/10.1002/9780470122921.ch2

Cooper, D.J., Rajahram, G.S., William, T., Jelip, J., Mohammad, R., Benedict, J., Alaza, D.A., Malacova, E., Yeo, T.W. \& Grigg, M.J. (2020). Plasmodium knowlesi Malaria in Sabah, Malaysia, 2015-2017: Ongoing increase in incidence despite near-elimination of the human-only Plasmodium Species. Clinical Infectious Diseases 70: 361-367. https:// doi.org/10.1093/cid/ciz237

Doolan, D.L., Southwood, S., Freilich, D.A., Sidney, J., Graber, N.L., Shatney, L., Bebris, L., Florens, L., Dobono C. \& Witney, A.A. (2003). Identification of Plasmodium falciparum antigens by antigenic analysis of genomic and proteomic data. Proceedings of the National Academy of Sciences of the United States of America 100: 9952-9957. https://doi.org/ 10.1073/pnas.1633254100

Doytchinova, I.A. \& Flower, D.R. (2007). VaxiJen: a server for prediction of protective antigens, tumour antigens and subunit vaccines. BMC Bioinformatics 8: 4. https://doi.org/ 10.1186/1471-2105-8-4

Durojaye, O., Joshua, P., Cosmas, S., Ugochi, N., Okagu, I., Collins, D. \& Chisom, A. (2018). A reverse vaccinology approach in the identification of potential vaccine candidates from Plasmodium falciparum erythrocyte membrane protein 1. Pharmacologyonline 3: 23-36.

Emini, E.A., Hughes, J.V., Perlow, D.S. \& Boger, J. (1985). Induction of hepatitis A virus-neutralizing antibody by a virus-specific synthetic peptide. Journal of Virology 55: 836839. https://doi.org/10.1128/JVI.55.3.836-839.1985
Galanis, K.A., Nastou, K.C., Papandreou, N.C., Petichakis, G.N., Pigis, D.G. \& Iconomidou, V.A. (2021). Linear B-cell epitope prediction for in silico vaccine design: A performance review of methods available via command-line interface. International Journal of Molecular Sciences 22. https://doi.org/ 10.3390/ijms22063210

Galanis, K.A., Nastou, K.C., Papandreou, N.C., Petichakis, G.N. \& Iconomidou, V.A. (2019). Linear B-cell epitope prediction: a performance review of currently available methods. BioRxiv 833418 [Preprint]. https://doi.org/10.1101/833418

Gasteiger, E., Hoogland, C., Gattiker, A., Duvaud, S., Wilkins, M., Appel, R. \& Bairoch, A. (2005). Protein Identification and Analysis Tools on the ExPASy Server. In: The Proteomics Protocols Handbook, Walker, J.M. (editor). Totowa, NJ: Humana Press, pp. 571-607.

Goh, X.T., Lim, Y.A., Vythilingam, I., Chew, C.H., Lee, P.C., Ngui, R., Tan, T.C., Yap, N.J., Nissapatorn, V. \& Chua, K.H. (2013). Increased detection of Plasmodium knowlesi in Sandakan division, Sabah as revealed by PlasmoNex ${ }^{\mathrm{TM}}$. Malaria Journal 12: 264. https://doi.org/10.1186/1475-2875-12-264

Haron, F.N., Azazi, A., Chua, K.H., Lim, Y.A.L., Lee, P.C. \& Chew, C.H. (2020). Small-scale optimization of recombinant Plasmodium knowlesi apical membrane antigen 1 (rPkAMA1) expression in Pichia pastoris. Asian Journal of Medicine and Biomedicine 4: 79-90.

Hodder, A.N., Crewther, P.E., Matthew, M.L., Reid, G.E., Moritz, R.L., Simpson, R.J. \& Anders, R.F. (1996). The disulfide bond structure of Plasmodium apical membrane antigen1. Journal of Biological Chemistry 271: 29446-29452. https:// doi.org/10.1074/jbc.271.46.29446

Jahangiri, F., Jalallou, N. \& Ebrahimi, M. (2019). Analysis of apical membrane antigen (AMA)-1 characteristics using bioinformatics tools in order to vaccine design against Plasmodium vivax. Infection, genetics and evolution 71: 224231. https://doi.org/10.1016/j.meegid.2019.04.001

Janin, J., Wodak, S., Levitt, M. \& Maigret, B. (1978). Conformation of amino acid side-chains in proteins. Journal of Molecular Biology 125: 357-386. https://doi.org/10.1016/0022-2836(78) 90408-4

Jespersen, M.C., Peters, B., Nielsen, M. \& Marcatili, P. (2017). BepiPred-2.0: improving sequence-based B-cell epitope prediction using conformational epitopes. Nucleic Acids Research 45: W24-W29. https://doi.org/10.1093/nar/gkx346

Karplus, P.A. \& Schulz, G.E. (1985). Prediction of chain flexibility in proteins. Naturwissenschaften 72: 212-213. https://doi. org/10.1007/BF01195768

Kolaskar, A.S. \& Tongaonkar, P.C. (1990). A semi-empirical method for prediction of antigenic determinants on protein antigens. FEBS Letters 276: 172-174. https://doi.org/ 10.1016/0014-5793(90)80535-q

Laurens, M.B., Thera, M.A., Coulibaly, D., Ouattara, A., Kone, A.K., Guindo, A.B., Traore, K., Traore, I., Kouriba, B. \& Diallo, D.A. (2013). Extended safety, immunogenicity and efficacy of a blood-Stage malaria vaccine in Malian children: 24month follow-up of a randomized, double-blinded phase 2 trial. PLoS One 8: e79323. https://doi.org/10.1371/ journal.pone.0079323

Lee, P.C., Chong, E.T., Anderios, F., Al Lim, Y., Chew, C.H. \& Chua, K.H. (2015). Molecular detection of human Plasmodium species in Sabah using PlasmoNex ${ }^{\mathrm{TM}}$ multiplex PCR and hydrolysis probes real-time PCR. Malaria Journal 14: 28. https://doi.org/10.1186/s12936-015-0542-5 
López, C., Yepes-Pérez, Y., Díaz-Arévalo, D., Patarroyo, M.E. \& Patarroyo, M.A. (2018). The in vitro antigenicity of Plasmodium vivax rhoptry neck protein 2 (PVRON2) B- and Tepitopes selected by HLA-DRB1 binding profile. Frontiers in Cellular and Infection Microbiology 8: 156. https://doi.org/ 10.3389/fcimb.2018.00156

Mahdi Abdel Hamid, M., Remarque, E.J., van Duivenvoorde, L.M., van der Werff, N., Walraven, V., Faber, B.W., Kocken, C.H. \& Thomas, A.W. (2011). Vaccination with Plasmodium knowlesi AMA1 formulated in the novel adjuvant covaccine $\mathrm{HT}^{\mathrm{TM}}$ protects against blood-stage challenge in rhesus macaques. PloS One 6: e20547. https://doi.org/ 10.1371/journal.pone.0020547

Millar, S.B. \& Cox-Singh, J. (2015). Human infections with Plasmodium knowlesi - zoonotic malaria. Clinical Microbiology and Infection 21: 640-648. https://doi.org/10.1016/ j.cmi.2015.03.017

Motamedpour, L., Dalimi, A., Pirestani, M. \& Ghaffarifar, F. (2020). In silico analysis and expression of a new chimeric antigen as a vaccine candidate against cutaneous leishmaniasis. Iranian Journal Basic Medical Sciences 23: 1409-1418. https://doi.org/10.22038/ijbms.2020.45394.10561

Nascimento, I.P. \& Leite, L.C. (2012). Recombinant vaccines and the development of new vaccine strategies. Brazilian Journal of Medical and Biological Research 45: 1102-1111. https://doi.org/10.1590/s0100-879×2012007500142

Pain, A., Böhme, U., Berry, A.E., Mungall, K., Finn, R.D., Jackson, A.P., Mourier, T., Mistry, J., Pasini, E.M. \& Aslett, M.A. (2008). The genome of the simian and human malaria parasite Plasmodium knowlesi. Nature 455: 799-803. https://doi. org/10.1038/nature07306

Parker, J.M., Guo, D. \& Hodges, R.S. (1986). New hydrophilicity scale derived from high-performance liquid chromatography peptide retention data: correlation of predicted surface residues with antigenicity and X-ray-derived accessible sites. Biochemistry 25: 5425-5432. https://doi. org/10.1021/bi00367a013

Pellequer, J.-L., Westhof, E. \& Van Regenmortel, M.H. (1993). Correlation between the location of antigenic sites and the prediction of turns in proteins. Immunology Letters 36: 83-99. https://doi.org/10.1016/0165-2478(93)90072-a

Ponnuswamy, P.K., Prabhakaran, M. \& Manavalan, P. (1980). Hydrophobic packing and spatial arrangement of amino acid residues in globular proteins. Biochimica et Biophysica Acta (BBA)-Protein Structure 623: 301-316. https://doi.org/ 10.1016/0005-2795(80)90258-5

Reynisson, B., Alvarez, B., Paul, S., Peters, B. \& Nielsen, M. (2020). NetMHCpan-4.1 and NetMHCllpan-4.0: improved predictions of MHC antigen presentation by concurrent motif deconvolution and integration of MS MHC eluted ligand data. Nucleic Acids Research 48: W449-W454. https://doi.org/10.1093/nar/gkaa379

Saha, S. \& Raghava, G.P. (2006). Prediction of continuous B-cell epitopes in an antigen using recurrent neural network. Proteins: Structure, Function, and Bioinformatics 65: 40-48. https://doi.org/10.1002/prot.21078

Saha S. \& Raghava G.P.S. (2004) BcePred: Prediction of continuous B-Cell epitopes in antigenic sequences using physico-chemical properties. $3^{\text {rd }}$ International Conference Artificial Immune Systems, ICARIS. Catania, Sicily, Italy.

Sanchez-Trincado, J.L. Gomez-Perosanz, M. \& Reche, P.A. (2017). Fundamentals and methods for T- and B-Cell epitope prediction. Journal of Immunology Research 2017: 2680160. https://doi.org/10.1155/2017/2680160
Silvie, O., Franetich, J.F., Charrin, S., Mueller, M.S., Siau, A., Bodescot, M., Rubinstein, E., Hannoun, L., Charoenvit, Y. \& Kocken, C.H. (2004). A role for apical membrane antigen 1 during invasion of hepatocytes by Plasmodium falciparum sporozoites. Journal of Biological Chemistry 279: 9490-9496. https://doi.org/10.1074/jbc.M311331200

Singh, S.P., Khan, F. \& Mishra, B.N. (2010). Computational characterization of Plasmodium falciparum proteomic data for screening of potential vaccine candidates. Human Immunology 71: 136-143. https://doi.org/10.1016/j.humimm. 2009.11.009

Sirima, S.B., Durier, C., Kara, L., Houard, S., Gansane, A., Loulergue, P., Bahuaud, M., Benhamouda, N., Nebié, I. \& Faber, B. (2017). Safety and immunogenicity of a recombinant Plasmodium falciparum AMA1-DiCo malaria vaccine adjuvanted with GLA-SE or Alhydrogel ${ }^{\circledR}$ in European and African adults: A phase $1 \mathrm{a} / 1 \mathrm{~b}$, randomized, double-blind multi-centre trial. Vaccine 35: 6218-6227. https://doi.org/10.1016/j.vaccine.2017.09.027

Soria-Guerra, R.E., Nieto-Gomez, R., Govea-Alonso, D.O. \& Rosales-Mendoza, S. (2015). An overview of bioinformatics tools for epitope prediction: implications on vaccine development. Journal of Biomedical Informatics 53: 405-414. https://doi.org/10.1016/j.jbi.2014.11.003

Stern, L.J. \& Calvo-Calle, J.M. (2009). HLA-DR: molecular insights and vaccine design. Current Pharmaceutical Design 15: 32493261. https://doi.org/10.2174/138161209789105171

Triglia, T., Healer, J., Caruana, S.R., Hodder, A.N., Anders, R.F., Crabb, B.S. \& Cowman, A.F. (2000). Apical membrane antigen 1 plays a central role in erythrocyte invasion by Plasmodium species. Molecular Microbiology 38: 706-718. https://doi.org/10.1046/j.1365-2958.2000.02175.x

Urquiza, M., Suarez, J.E., Cardenas, C., Lopez, R., Puentes, A., Chavez, F., Calvo, J.C. \& Patarroyo, M.E. (2000). Plasmodium falciparum AMA-1 erythrocyte binding peptides implicate AMA-1 as erythrocyte binding protein. Vaccine 19: 508-513. https://doi.org/10.1016/S0264-410X(00)00185-7

Vita, R., Mahajan, S., Overton, J.A., Dhanda, S.K., Martini, S., Cantrell, J.R., Wheeler, D.K., Sette, A. \& Peters, B. (2019). The Immune Epitope Database (IEDB): 2018 update. Nucleic Acids Research 47: D339-D343. https://doi.org/ 10.1093/nar/gky1006

World Health Organization. (2020). World Malaria Report 2020: 20 years of global progress and challenges. Geneva: World Health Organization.

Yang, A.S., Lopaticki, S., O’Neill, M.T., Erickson, S.M., Douglas, D.N., Kneteman, N.M. \& Boddey, J.A. (2017). AMA1 and MAEBL are important for Plasmodium falciparum sporozoite infection of the liver. Cellular Microbiology 19: e12745. https://doi.org/10.1111/cmi.12745

Zaharieva, N., Dimitrov, I., Flower, D. \& Doytchinova, I.A. (2017). Immunogenicity prediction by VaxiJen: A ten year overview. Journal of Proteomics \& Bioinformatics 10: 298-310. https:// doi.org/10.4172/jpb.1000454

Zaw, M.T. \& Lin, Z. (2019). Human Plasmodium knowlesi infections in South-East Asian countries. Journal of Microbiology, Immunology, and Infection 52: 679-684. https:// doi.org/10.1016/j.jmii.2019.05.012

Zawawi, A., Forman, R., Smith, H., Mair, I., Jibril, M., Albaqshi, M.H., Brass, A., Derrick, J.P. \& Else, K.J. (2020). In silico design of a T-cell epitope vaccine candidate for parasitic helminth infection. PLoS Pathogens 16: e1008243. https:// doi.org/10.1371/journal.ppat.1008243

Zobayer, N., Hossain, A.A. \& Rahman, M.A. (2019). A combined view of B-cell epitope features in antigens. Bioinformation 15: 530-534. https://doi.org/10.6026/97320630015530 